\title{
O lugar da composição musical no ensino artístico especializado da música em
}

\section{Portugal}

\author{
The place of musical composition in the specialized artistic teaching of music in Portugal \\ El lugar de la composición musical en las enseñanzas artísticas especializadas de música en \\ Portugal
}

Recebido: 09/01/2022 | Revisado: 12/01/2022 | Aceito: 19/01/2022 | Publicado: 22/01/2022

\author{
José Augusto Neves de Moura \\ ORCID: https://orcid.org/0000-0002-6170-8737 \\ Universidade do Minho, Portugal \\ Centro de Investigação em Estudos da Criança, Portugal \\ E-mail: josemoura69@gmail.com \\ António José Pacheco Ribeiro \\ ORCID: https://orcid.org/0000-0003-3413-8473 \\ Universidade do Minho, Portugal \\ Centro de Investigação em Estudos da Criança, Portugal \\ E-mail: antoniopacheco@ie.uminho.pt
}

\begin{abstract}
Resumo
A disciplina de Composição e o Curso de Composição assumem um papel importante no currículo do ensino artístico especializado da música, em Portugal, que se manifesta desde a criação do Conservatório de Lisboa, ligado à Casa Pia (1835), até aos dias de hoje. Este artigo descreve um capítulo do doutoramento em Educação Artística - Educação Musical do Programa de Doutoramento em Estudos da Criança da Universidade do Minho e tem como objetivo principal fazer um estudo da evolução histórica do Curso de Composição e respetivas disciplinas análogas, no âmbito do ensino artístico especializado da música, através de uma análise cronológica das diferentes reformas curriculares ocorridas desde a fundação do Conservatório de Lisboa, até à última reforma ocorrida com o Decreto-Lei nº 310/83, de 1 de julho, e a subsequente reestruturação que se mantém até aos dias de hoje. Como objetivo específico, pretende-se situar o atual estado da arte em que a disciplina de Composição e o Curso de Composição se encontram nas escolas de ensino artístico especializado da música em Portugal. A metodologia adotada privilegiou a análise de conteúdo da legislação publicada para o ensino da música, bem como outra documentação considerada pertinente para fundamentar o trabalho.

Palavras-chave: Composição musical; Evolução histórica; Ensino artístico especializado da música; Reformas curriculares.
\end{abstract}

\begin{abstract}
The Composition discipline and the Composition Course assume an important role in the curriculum of the specialized artistic teaching of music, in Portugal, which manifests itself since the creation of the Lisbon Conservatory, linked to Casa Pia (1835), until today. This article describes a chapter of the PhD in Artistic Education - Music Education of the $\mathrm{PhD}$ Program in Child Studies of the University of Minho and has as main objective to make a study of the historical evolution of the Composition Course and its analogous disciplines, within the specialized artistic teaching of music, through a chronological analysis of the different curricular reforms occurred since the foundation of the Conservatory of Lisbon, until the last reform occurred with the Decree-Law No. 310/83, of July 1, and the subsequent restructuring that remains to this day. As a specific objective, it is intended to situate the current state of the art in which the Composition discipline and the Composition Course are found in the specialized music schools in Portugal. The methodology adopted has privileged the analysis of the content of the legislation published for the teaching of music, as well as other documentation considered pertinent to substantiate the work.
\end{abstract}

Keywords: Musical composition; Historical evolution; Specialized artistic teaching of music; Curricular reforms.

\section{Resumen}

La disciplina de Composición y el Curso de Composición asumen un papel importante en el currículo de la enseñanza artística especializada de la música, en Portugal, que se manifiesta desde la creación del Conservatorio de Lisboa, vinculado a la Casa Pia (1835), hasta la actualidad. Este artículo describe un capítulo de la tesis doctoral en Educación Artística - Educación Musical del Programa de Doctorado en Estudios del Niño de la Universidad de Minho y tiene como objetivo principal hacer un estudio de la evolución histórica del Curso de Composición y de las respectivas disciplinas análogas, en el contexto de las enseñanzas artísticas especializadas en música, a través de un análisis cronológico de las diferentes reformas curriculares que se han producido desde la fundación del Conservatorio de 
Lisboa, hasta la última reforma ocurrida con el Decreto-Ley n ${ }^{\circ}$ 310/83, de 1 de julio, y la posterior reestructuración que continúa hasta nuestros días. Como objetivo específico, se pretende situar el estado actual en el que se encuentra la disciplina de Composición y el Curso de Composición en las escuelas de enseñanza artística especializada de música en Portugal. La metodología adoptada privilegió el análisis de contenido de la legislación publicada para la enseñanza de la música, así como otra documentación que se consideró pertinente para fundamentar el trabajo.

Palabras clave: Composición musical; Evolución histórica; Enseñanza artística especializada de la música; Reformas curriculares.

\section{Introdução}

O ensino da música em Portugal desenvolve-se desde a fundação do reino, século XII, até aos nossos dias, em diferentes contextos. A criação do Conservatório de Música de Lisboa, ligado à casa Pia (1835), assinala um marco importante de viragem, pois transfere o ensino da música ministrado, até então, na esfera religiosa para a esfera púbica. No final da década de 80 do século XX, surge um novo modelo de ensino da música, designadamente o ensino profissional com a finalidade, exclusiva, de formar músicos instrumentistas para integrarem as orquestras. Este artigo converge no âmbito do ensino artístico especializado da música cuja oferta formativa contempla cursos de composição, neste contexto organiza-se nos seguintes tópicos: (i) O Ensino da Música desde a Fundação do Reino à Instituição do Conservatório de Música em Lisboa; (ii) O Ensino Musical da Composição: da Fundação do Conservatório 1835 até à Atualidade; (iii) 3. O Conservatório de Música de Braga Calouste Gulbenkian: um Novo Paradigma do Ensino da Composição, e apresenta os seguintes objetivos: perceber qual o lugar do Curso de Composição e respetivas disciplinas análogas, no âmbito do ensino artístico especializado da música, e situar o atual estado da arte em que a disciplina de Composição e o Curso de Composição se encontram nas escolas de ensino artístico especializado da música, em Portugal.

\section{Metodologia}

A metodologia adotada para a realização deste estudo centrou-se na pesquisa bibliográfica de carácter narrativo e qualitativo, própria para fazer uma revisão da literatura sobre o assunto. Este tipo de método constitui-se por uma análise alargada da literatura, no entanto não apresenta uma metodologia rigorosa e capaz de se replicar ao nível da reprodução de dados e quantificação das respostas (Vosgerau \& Romanowski, 2014), assim como não utiliza critérios explícitos e sistemáticos para a busca e análise da literatura. De acordo com Severino (2014) a pesquisa bibliográfica realiza-se com base em documentos já disponíveis, tais como como, livros, teses, dissertações e artigos científicos.

A revisão da literatura para o presente estudo convergiu na análise bibliográfica de livros, artigos, teses e legislação sobre o ensino da música, pois foram estes documentos os considerados pertinentes para a obtenção de informação sobre o lugar da composição musical no ensino artístico especializado da música em Portugal.

\section{O Ensino da Música desde a Fundação do Reino à Instituição do Conservatório de Música em}

\section{Lisboa}

Desde a fundação do reino até ao século XVIII, o ensino da música em Portugal foi essencialmente ministrado no âmbito da Igreja (Carneiro \& Vieira, 2017). Desde os primórdios da nacionalidade, a música sempre esteve presente nas universidades medievais, sendo os seus maiores mestres os próprios clérigos. Apesar das constantes censuras impostas pela Igreja no que diz respeito à música, nomeadamente Índex e Inquisição, o ensino da música foi sempre considerado deficiente mantendo-se desta forma durante vários séculos. Durante toda a idade média, o ensino da música era ministrado nas universidades como parte 
integrante do quadrivium ${ }^{1}$. Apesar de se saber muito pouco sobre este tipo de ensino, sabemos que era fundamentalmente teórico e lecionado, sobretudo, sobre uma componente mais analítica em detrimento de uma perspetiva mais prática, sendo que até ao aparecimento das primeiras universidades, o ensino era ministrado nos grandes mosteiros. "No século XII, um movimento de retorno ao ideal ascético das ordens de Cluny e de Cister diminuía essa acção pedagógica, reduzindo-a a fins práticos" (Freitas Branco, 1995, p. 65).

Em 1290, o rei D. Dinis, na sequência de diligencias realizadas ao Papa, oficializa o Estudo Geral de Lisboa, que deu origem à primeira universidade do reino, em que se ministrava o ensino da música, e teve como modelo a universidade pontifica de Salamanca, fundada em 1215.

Durante a reforma ordenada por D. Manuel, e com a Inquisição, vamos assistir a uma gradual diminuição da autonomia da universidade, devido às circunstâncias em que o país atravessava, nomeadamente a nível económico, dado que a prática polifónica exigia despesas que só a capela real e a capela dos infantes poderiam suportar. Outro aspeto, neste sentido, deveu-se à pouca importância que a disciplina de música tinha; a Igreja continua a ser a única instituição a dar continuidade a uma educação musical sistematizada.

Durante o século XVI, surgem em várias igrejas e sés as primeiras organizações com vista a um ensino sistemático da música em Portugal (Brito \& Cymbron, 1992). Desta forma surgem as escolas de música das Sés de Évora, Elvas, Portalegre, Braga e do Porto. No caso da Sé Catedral do Porto sabe-se hoje que a sua escola: "ficou conhecida por ter sido um caso notável de organização, com mestres competentes e pelo fato dos seus alunos, jovens moços de coro, não aprenderem apenas música vocal, mas também a execução de alguns instrumentos, incluindo naturalmente, o órgão" (Amado, 1999, p. 35). A mais importante durante o século XVI é a Escola de Música da Sé de Évora onde se destacam os seguintes mestres de capela ou mestres da clausura: Mateus de Aranda entre 1524-1544, ano em que foi nomeado para a cátedra de música da Universidade de Coimbra, Manuel Mendes (1578-1589), Filipe de Magalhães (1589-1604) e Diogo Melgás (1663-1700). Pode dizer-se que durante um período de quase dois séculos e ao longo de três gerações, a Escola de Música da Sé de Évora constituiu o principal centro de formação de compositores em Portugal.

A Companhia de Jesus foi fundada por Inácio de Loyola em 1534, no entanto, a sua ação pedagógica situou-se mais ao nível da propaganda didática, recorrendo à música para alcançar os seus fins, do que ao nível de uma educação musical efetiva, chegando a componente musical a ser mesmo proibida nas celebrações religiosas. $\mathrm{O}$ regulamento de 1558 ainda proibia a guarda de instrumentos musicais e alguns utensílios que não eram considerados pertinentes para o serviço da ordem.

Em Vila Viçosa, por intermédio de D. Teodósio II, Duque de Bragança e pai de D. João II de Bragança, futuro Rei D. João IV, é fundado o Colégio dos Reis destinado ao ensino da música. Só no reinado de D. João V é que se vai operar uma profunda reforma no ensino da música, com influência operática italiana, “[...] uma profunda reforma nos domínios da música, introduzindo a ópera e as novas formas instrumentais, criando a escola de música da Patriarcal, enviando a Itália pensionistas seleccionados, [e] contratando grandes mestres estrangeiros" Ccruz, 1985, p. 210).

As capelas musicais, até à revolução liberal (1834), vão continuar a existir em quase todas as dioceses portuguesas. Em 1785 a capela musical da Sé de Évora tinha dois organistas, três violinistas, dois violoncelistas, dois baixões, três contraltos, quatro tenores e três baixos. Até ao ano de 1800 todos os elementos atuavam com regularidade como cantores, exceto os dois organistas. O ano de 1834 é um ano fundamental, pois marca uma nova época ao nível do ensino da música com a extinção do Seminário da Patriarcal, em Lisboa, iniciando desta forma a laicização deste tipo de ensino (Gomes, 2000).

\footnotetext{
${ }^{1}$ Do latim quadriviu (lugar em que se juntam quatro caminhos ou ruas). Na Idade Média, um dos dois ramos em que a filosofia escolástica dividia as ciências, e que era constituído pelas disciplinas de Aritmética, Geometria, Astronomia e Música, ensinadas nas universidades helénicas.
} 


\subsection{O Ensino Musical da Composição: da Fundação do Conservatório 1835 até à Atualidade}

O Conservatório de Música de Lisboa, ligado à Casa Pia, foi fundado em 1835 e vem ocupar o lugar extinto do Seminário da Patriarcal, no que diz respeita à formação de músicos profissionais.

Por Decreto de 5 de Maio de 1835 é criado em Lisboa um Conservatório de Música que substitui, na formação de músicos profissionais, o Seminário da Patriarcal extinto em 1834. Este Conservatório, anexo à Casa Pia [...], possui como características inovadoras o visar de uma acção caritativa assim como pretende ministrar uma formação laica a ambos os sexos (Gomes, 2000, p. 17).

O Conservatório de Música de Lisboa, ligado à Casa Pia, herda este sentido e desenvolve-se neste âmbito de ação. Estamos perante uma grande influência do modelo filantrópico dos conservatórios italianos dos séculos XVII e XVIII e, consequentemente, mais distante da escola musical do Conservatório de Paris. Neste contexto, é de supor que o conceito de ensino especializado da música tenha nascido no século XIX e a criação do Conservatório tenha sido, também, uma primeira tentativa de generalizar e democratizar este tipo de ensino, até então, praticado exclusivamente nas instituições religiosas (Pacheco, 2013). A Direção do Conservatório foi atribuída ao músico português João Domingos Bomtempo (1775-1842) e a falta de meios humanos e económicos levou a que o Conservatório tivesse ficado com a maior parte do corpo docente do antigo Seminário da Patriarcal.

No que se refere aos cursos lecionados o artigo $1^{\circ}$ do Decreto de 5 de maio de 1835, segundo Gomes (2000, p. 18), diz o seguinte:

Artigo 1. ${ }^{\circ}$ Haverá na Casa Pia desta Capital um Conservatório de Música, que terá as Aulas seguintes: Primeira de Preparatórios, e rudimentos: Segunda de Instrumentos de latão: Terceira de Instrumentos de palheta: Quarta de Instrumentos de arco: Quinta de Orquestra: Sexta de Canto.

O regulamento da fundação do Conservatório de Música de Lisboa, ligado à Casa Pia, não contemplava qualquer referência ao curso de Composição ou disciplinas relacionadas com a Composição. O Conservatório de Música de Lisboa, então criado, pressupostamente não atingiu os seus fins e foi incorporado, em 1836, no Conservatório Geral de Arte Dramática, instituição criada à imagem do Conservatoire Nationel de Music et de Déclamation de Paris (1795).

Por Decreto Real de 15 de Novembro de 1836, mandado publicar pela rainha D. Maria II (A Educadora), foi criado o Conservatório Geral da Arte Dramática. Tinha como diretor Almeida Garrett e integrava três escolas: a Escola de Música, cuja direção continuou a cargo de Domingos Bomtempo; a Escola Dramática de Teatro ou de Declamação; e a Escola de Dança, Mímica e Ginástica Especial (Nogueira, 2016, p. 13).

Os primeiros anos de atividade do Conservatório foram bastantes difíceis em termos financeiros e pelo desinteresse demonstrado pelo reino. Neste sentido, após a nomeação do Rei D. Fernando (1840), como presidente honorário do Conservatório, este passou a designar-se Conservatório Real de Lisboa (Nogueira, 2016).

Durante o século XIX encontramos um conjunto de reformas e contrarreformas ditadas mais por questões de ordem económica do que pedagógica. A primeira destas reformas verificou-se, ainda, no âmbito do mencionado Conservatório Geral de Arte Dramática tendo-o dividido em três escolas: uma de declamação, uma de música e outra de dança. O artigo $24 .^{\circ}$ do Decreto de 27 de março de 1839, de acordo com Gomes (2000, p. 19), diz o seguinte:

a Eschola especial de musica consta das doze aulas seguintes: $1 .^{\mathrm{a}}$ de Contraponto, e Composição; $2 .^{\mathrm{a}}$ Piano, Harmonia e suas accessorias; $3 .^{a}$ de Harpa; $4 .^{\text {a }}$ de Canto para o sexo feminino; $5 .^{a}$ de Canto para o sexo masculino; $6 .^{a}$ de Rebeca,

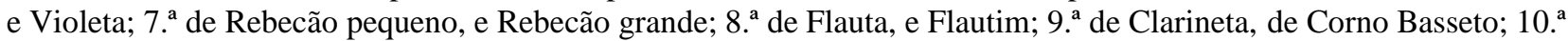




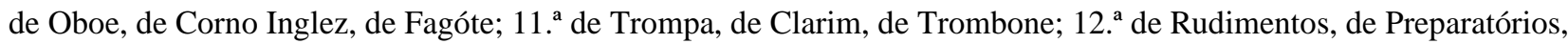
e de Solfejos.

Neste sentido, verifica-se, pela primeira vez, que a escola de música do Conservatório Geral de Arte Dramática comportava no seu currículo cursos de Contraponto e Composição e de Piano e Harmonia.

As dificuldades económicas persistiam e, neste contexto, em 1869, a Escola de Dança do Conservatório Real de Lisboa foi extinta, com o objetivo de reduzir a despesa pública. Verificaram-se, igualmente, algumas modificações na Escola de Música, passando a ser ministrados, de acordo com o citado no artigo 6. do Decreto de 29-12-1869, os seguintes cursos: "[...] de rudimentos e solfejo, de canto, de piano, rabeca e violeta, violoncello e contrabaixo, flauta e flautim, instrumentos de palheta, instrumentos de metal, de harmonia, melodia e contraponto" (Nogueira, 2016, p. 16).

No âmbito das reformas mencionadas, a Carta de Lei de 25 de agosto de 1887, promulgada pelo Rei D. Luiz, vem autorizar o governo a reformar o Conservatório Real de Lisboa. Assim, os Decretos de 6 de dezembro de 1888 e de 20 de março de 1890 veem reformar o currículo da escola de música havendo pela primeira vez a indicação expressa da duração, em anos, dos diversos cursos e disciplinas. O artigo 2. ${ }^{\circ}$ do Decreto de 6 de dezembro de 1888 (Gomes, 2000, p. 21) diz o seguinte:

o ensino da musica compõe-se do seguinte: $1 .{ }^{\circ}$ Rudimentos; $2 .{ }^{\circ}$ Solfejo; $3 .{ }^{\circ}$ Canto Coral; $4 .^{\circ}$ Canto; $5 .{ }^{\circ}$ Piano; $6 .{ }^{\circ}$ Rabeca; 7. ${ }^{\circ}$ Violeta; $8 .^{\circ}$ Violoncello; $9 .^{\circ}$ Contrabaixo; $10 .^{\circ}$ Flauta; $11 .{ }^{\circ}$ Clarinete; $12 .{ }^{\circ}$ Oboé e corn' inglez; $13 .{ }^{\circ}$ Fagote; $14 .{ }^{\circ}$ Saxophone; $15 .^{\circ}$ Trompa; $16 .^{\circ}$ Clarim; $17 .^{\circ}$ Cornetim; $18 .^{\circ}$ Trombone; $19 .{ }^{\circ}$ Sax-horne; $20 .^{\circ}$ Harmonia; $21 .^{\circ}$ Contraponto e composição.

O Decreto de 20 de março de 1890 vem indicar a duração dos diferentes cursos/disciplinas. Neste sentido, verifica-se que, nesta reforma, aparece uma nova disciplina/curso: Harmonia, correspondendo a um Curso Geral com a duração de 3 anos, e o Curso de Contraponto e Composição compreende a especialidade Complementar com a duração de 5 anos (Gomes, 2000).

Em 1898, o Conservatório Real de Lisboa sofre uma nova reforma através dos Decretos de 13 de janeiro de 1898 e de 28 de julho de 1898. Desta forma, o Decreto de 13 de janeiro de 1898 veio modificar a estrutura do ensino da música ministrado no Conservatório Real de Lisboa, criando, para quase todos os instrumentos, cursos gerais e superiores. Neste âmbito, o curso de Harmonia passa a corresponder a um Curso Especial com a duração de 3 anos e o curso de Contraponto, Fuga e Composição passa a ter a duração de 4 anos e considerado Especial (Gomes, 2000; Nogueira, 2016). Nesta reforma, como podemos observar, a Harmonia, a Composição e o Contraponto continuam a fazer parte do currículo e é incluída a Fuga.

Os estatutos do Conservatório Real de Lisboa, no que diz respeito ao ensino da música, permaneceram basicamente inalterados até 1901. É com Augusto Machado (1845-1924), diretor da Escola de Música de 1901 a 1910 , que surge uma importante reforma posteriormente plasmada no Decreto de 24 de outubro de 1901. Esta reforma colocou o Conservatório nos caminhos da modernidade, atualizando planos de estudo e reportórios para os diversos instrumentos. Desta reforma resultou a alteração e duração de alguns cursos, criando a distinção entre instrumentos de primeira e de segunda e eliminando todos os cursos superiores de instrumento, previstos pelo anterior Decreto de 13 de janeiro de 1898, à exceção do de Piano, Violino e Violoncelo. No que concerne aos cursos de Harmonia e de Contraponto, Fuga e Composição, estes, mantiveram as durações da reforma anterior, concretamente 3 e 4 anos, no entanto perderam a designação de Especial (Gomes, 2000; Nogueira, 2016).

No início do Século XX, após a implementação da República (1910), o Conservatório Real de Lisboa passou a designarse Conservatório Nacional de Lisboa. A implementação da República conduziu a alterações importantes no ensino e na cultura. Como refere Vasconcelos (2002, p. 52) “[...] nas primeiras décadas do século XX, procurou-se reorganizar os estudos ministrados no Conservatório Nacional, não só adaptando a sua formação às exigências da altura como também possibilitando o alargamento na concepção da formação do músico". Neste contexto, em 1919, o Conservatório sofreu uma importante e inovadora reforma, instituída pelos Decretos nº 5546 e 6129, respetivamente de 9 de maio e de 25 de setembro de 1919 (Gomes, 2000), levada a 
cabo pelo pianista Viana da Mota (que ficou como seu diretor) conjuntamente com Luís de Freitas Branco. Neste sentido, foi elaborado "[...] um currículo de formação geral e musical e a obrigatoriedade de uma prática musical regular para alunos e professores" (Latino, 1986 citado por Palheiros, 1993, p. 39). Os programas e os métodos pedagógicos foram modernizados “[...] fornecendo aos alunos meios de obtenção de uma cultura menos rudimentar do que era regra entre os músicos portugueses" (Freitas Branco, 1995, p. 296). Viana da Mota vai ser muito importante na construção de um ideário que estará na base da formulação de propostas posteriores, como a apresentada em 1906 pelo Conservatório Nacional a pedido do Ministro da Educação Nacional, professor Doutor Galvão Teles, assim como na motivação de posições assumidas no Projeto de Reforma do Sistema Escolar, apresentado pelo ministro da Educação nacional, Professor Doutor José Veiga Simão, em janeiro de 1971 (Gomes, 2000).

O preâmbulo do Decreto $\mathrm{n}^{\circ}$ 5546, de 9 de maio de 1919, de acordo com Gomes (2000, pp. 27-28) vai estabelecer as bases motivacionais para a reforma agora realizada, começando por nos dizer que "a realidade dos factos, mais do que o pêso dos argumentos, é que há-de mostrar as vantagens da presente remodelação do Conservatório de Lisboa”. Continua dizendo que (Dec. n. ${ }^{\circ}$ 5546: preâmbulo):

os seus processos de ensino eram antiquados. A sua organização era defeituosa. O seu magistério mal retribuído. Ainda lá se adoptava, como iniciação musical, o ensino do solfejo rezado. Principiava-se o ensino da música por desinteressar os alunos do que as notas possuem de mais fundamental representativo - o som. A êste defeito inicial ligavam-se, com agravada intensidade, outras muitas e múltiplas incongruências. Não havia um curso privativo de composição, não havia cadeira de instrumentação, nem uma aula de regência de orquestra. Não se ministravam aos alunos noções de acústica, nem os princípios genéricos da estética musical, nem nenhuns preliminares das outras sciências musicais. Não se lhes proporcionava a aprendizagem de português, de história, de geografia e restante cultura geral que deve andar ligada ao ensino das especialidades. Nas aulas em que deveria prevalecer o ensino individual (piano, violino, violoncelo, etc.), o princípio pedagógico da limitação dos alunos era duma tam esticada elasticidade que estes recebiam, quanto muito, uma lição de dez a doze minutos por mês. Os próprios alunos, arvorados em monitores, ensinavam com sanção oficial os companheiros de escola, pegando-lhes defeitos de execução e outros erros, naturais em quem aprende ainda. A tudo isto e a muito mais procurou obviar o presente decreto.

A reforma instituída pelo Decreto n ${ }^{\circ}$ 5546, de 9 de maio de 1919, apresenta também ainda algumas vantagens que pretende obter. Dessas destacam-se: "a divisão dos diferentes cursos de instrumento e os de canto e composição em três graus distintos: elementar, complementar e superior" e ainda, a instituição do "[...] ensino da composição em cadeira separada e o de regência de orquestra, instrumentação, acústica e estética musical” (Gomes, 2000, p. 28).

A partir desta importante reforma musical, o ensino da Composição passou a ser constituído pelos seguintes cursos/disciplinas: Composição, na especialidade Elementar (Harmonia) com a duração de três anos; Composição, na especialidade Complementar (Contraponto, Cânone e Fuga) com a duração de dois anos; Composição, na especialidade Superior (Composição) com a duração de três anos (Gomes, 2000; Nogueira, 2016).

A conjuntura política da altura não permitiu o desenvolvimento deste currículo e em 1930 é publicado um decreto que rompe com as inovações da reforma e aprova um plano curricular "[...] que prescindiu na cultura geral e profissional de futuros compositores e intérpretes musicais" (Freitas Branco, 1995, p. 296), e marca um retrocesso nítido relativamente a estas mesmas inovações. Neste contexto, os Conservatórios de Música e de Teatro são fundidos e reintegrados numa instituição sob a mesma administração (Decreto no 18 461, de 14 de junho de 1930), e o Decreto ${ }^{\circ} 18$ 881, de 25 de setembro de 1930, concretiza a remodelação anunciada. O modelo curricular aprovado pelo referido decreto de 1930 passa a ser adotado pelo Conservatório Nacional e restantes Escolas de Música Públicas, Particulares e Cooperativas e haveria de vigorar durante mais de cinquenta anos (Pacheco, 2013).

Com esta reforma, a Composição ficou inscrita no plano de estudos da seguinte forma: curso/disciplina de Composição na especialidade Geral com a duração de três anos; curso/disciplina de Contraponto, Cânone, Fuga e Estética Musical, na 
especialidade Superior, com a duração de dois anos; curso/disciplina de Composição e Instrumentação, na especialidade Superior, com a duração de dois anos (Gomes, 2000; Nogueira, 2016).

\subsection{A Experiência Pedagógica de 71}

No início da década de 70, do século XX, durante a designada reforma de Veiga Simão, o sistema educativo português sofreu importantes transformações as quais se sentiram também no ensino da música. Em janeiro de 1971, o Ministério da Educação Nacional edita uma brochura, intitulada Projeto do Sistema Escolar, destinada a ser objeto de uma ampla discussão pública como forma de encontrar as bases para um largo consenso nacional, visando uma reforma profunda do sistema educativo português. Neste contexto, neste ano, o Conservatório Nacional entrou em regime de Experiência Pedagógica sendo os seus programas e planos de estudos reorganizados ao abrigo deste documento.

Na sequência da apresentação do Projecto do Sistema Escolar, e após a exoneração do Dr. Ivo Cruz do cargo de director, ainda antes do final do ano lectivo de 1970/71, o Conservatório Nacional é colocado em regime de experiência pedagógica, sendo para o efeito nomeada uma comissão orientadora presidida pela Dr. ${ }^{a}$ Madalena Perdigão (Gomes, 2000, pp. 61-62).

No ano letivo de 1973/1974 foram apresentados os respetivos planos de estudo que dividiram os cursos em: Geral, Complementar e Superior. Neste particular, a Composição passou a ocupar a seguinte distribuição: Curso Geral (5\%/6 anos), Curso Complementar ( $7^{\circ} / 8^{\circ}$ anos) e Curso Superior (Gomes, 2000, pp. 64-65).

A Experiência Pedagógica, pensada para funcionar durante o ano letivo 1971/1972, prolongou-se no tempo, na medida em que os seus planos de estudo nunca foram publicados no Diário da República. De facto, a Experiência Pedagógica prolongouse até à homologação dos respetivos planos de estudo, através da Portaria nº 370/98, de 29 de junho.

\subsection{A Reforma do Ensino da Música de 1983}

A reforma levada a cabo pelo Decreto-Lei $n^{\circ} 310 / 83$, de 1 de julho, inseriu as artes no sistema geral de ensino, criando um novo conceito de escola: a escola vocacional. Assim, foram criadas áreas vocacionais de Música e Dança e integradas no sistema de ensino preparatório e secundário. O Conservatório Nacional foi extinto e sucedeu-lhe a Escola de Música e a Escola de Dança que passaram a ministrar cursos básicos e secundários artísticos. Ao nível superior foram criadas as Escolas Superiores de Música, Cinema, Dança e Teatro - inseridas no âmbito do ensino superior politécnico. A reforma estrutural em causa concebeu um novo tipo de organização para o ensino especializado da música: a escola de música vocacional, subdividindo-se em dois subtipos correspondendo ao primeiro a escola básica e secundária e ao segundo a escola de nível superior.

Foram várias as consequências desta reforma. No que diz respeito à Música e Dança, a estrutura curricular única - onde se desenvolvia toda a formação desde o nível inicial ao terminal-desapareceu, deixando de se processar unicamente num mesmo estabelecimento de ensino. Mais concretamente, no âmbito do ensino especializado da música, a sua estruturação em conformidade com os níveis do ensino regular, implicou a desintegração desta estrutura curricular que se desenvolvia desta forma desde há muitos anos. Foram criados cursos Superiores na verdadeira aceção da palavra e do sentido, conferindo grau académico, inicialmente, bacharelato; hoje, licenciatura, mestrado e doutoramento.

Neste contexto, desenvolveram-se ao nível do ensino preparatório e secundário unificado, cursos gerais de Instrumento, para a Música, e o curso geral de Dança para o ensino da Dança (artigo $3^{\circ}, n^{\circ}$ s 1 e 2). Relativamente aos cursos complementares do ensino secundário, o ensino da música e o ensino da dança constituíram áreas específicas próprias, de caráter profissionalizante, nas suas vertentes e opções: Formação Musical, Instrumento, Canto e Dança (artigo $\left.4^{\circ}, n^{\circ} 1\right)$. 
Os planos de estudos dos cursos gerais e complementares de música viriam a ser regulados posteriormente por legislação específica (Portaria $\mathrm{n}^{\circ}$ 294/84, de 17 de maio). Contudo, ficaram claros os princípios aos quais estes deveriam obedecer, integrando as componentes de formação geral, formação específica e formação vocacional (Decreto-Lei n ${ }^{\circ}$ 310/83, de 1 de julho, artigo $\left.5^{\circ}, n^{\circ} 1\right)$. Estes cursos podiam ser frequentados em regime integrado, articulado e supletivo.

Considerando os planos de estudos homologados por esta reforma, verifica-se que o Curso de Composição desaparece dos currículos, e apenas a disciplina de Análise e Técnicas de Composição aparece no Curso Complementar de Música, inserida na componente de formação específica, com a duração de 3 anos: $10^{\circ}, 11^{\circ}$ e $12^{\circ}$ anos de escolaridade. $\mathrm{O}$ curso de Composição, que tinha um papel significativo antes da reforma, depois da reforma de 83, perde importância e apenas no ensino superior passou a ser ministrado.

\subsection{A Reestruturação do Ensino Artístico Especializado da Música de 2009}

A reestruturação do ensino artístico especializado da música, levada a cabo entre 2007 e 2009, introduziu mudanças significativas neste tipo de ensino (Ribeiro \& Vieira, 2016), no entanto, o plano de estudos não se alterou no que concerne ao Curso de Composição e à disciplina de Análise e Técnicas de Composição. É apenas em 2012, através da publicação da Portaria n $243-\mathrm{B} / 2012$, de 13 de agosto, que o plano de estudos do curso secundário de música permite as seguintes opções: instrumento, formação musical e composição, para além dos cursos secundários de canto e de canto gregoriano. No artigo $2^{\circ}$ da Portaria $n^{\circ}$ 243-B/2012, de 13 de agosto, podemos ler o seguinte:

1 - Os planos de estudos integram as componentes de formação geral, científica e técnica -artística.

2 - O plano de estudos do Curso Secundário de Música contempla as variantes de Instrumento, de Formação Musical e de Composição, sendo inerente a cada uma daquelas uma disciplina trienal distinta.

Como se pode observar a partir de 2012, o Curso de Composição no ensino secundário volta a ser opção no plano de estudos do curso de música. As disciplinas nucleares de cada curso: Instrumento, Formação Musical e Composição integram-se na componente de formação técnica-artística e são lecionadas com uma carga horária de 2 blocos de 45 minutos. A disciplina de Análise e Técnicas de Composição integra a componente de formação científica e é lecionada com uma carga horária de 3 bloco de 45 minutos. O curso secundário de música, nas vertentes expostas, tem a duração de 3 anos, correspondendo ao $10^{\circ}, 11^{\circ}$ e $12^{\circ}$ anos de escolaridade. Estes cursos podem ser frequentados em regime de ensino integrado, articulado e supletivo.

1 - Os cursos secundários de Dança, de Música, de Canto e de Canto Gregoriano podem ser frequentados em regime integrado, num estabelecimento de ensino ou em regime articulado em dois estabelecimentos de ensino.

2 - Os cursos secundários de Música, de Canto e de Canto Gregoriano podem ainda ser frequentados em regime supletivo, num estabelecimento de ensino, sendo a sua frequência restrita às componentes de formação científica e técnica -artística dos anexos II, III e IV, aplicando -se a tabela constante do anexo VI da presente portaria, da qual faz parte integrante (Artigo $3^{\circ}$, Portaria n ${ }^{\circ} 243-\mathrm{B} / 2012$, de 13 de agosto).

Em virtude da reestruturação levada a cabo no ensino genérico, com a publicação do Decreto-Lei no 55/2018, de 6 de julho, o ensino artístico especializado da música sofreu uma atualização dos seus planos de estudo. Neste sentido, o curso secundário de música é hoje regulado pela Portaria n 229-A/2018, de 14 de agosto, em conformidade com a matriz curricular base dos cursos artísticos especializados prevista no anexo VII ao Decreto- -Lei n ${ }^{\circ} 55 / 2018$, de 6 de julho. Os planos de estudos então aprovados contemplam as seguintes áreas de formação:

a) A componente de formação geral, que visa contribuir para a construção da identidade pessoal, social e cultural dos alunos; 
b) A componente de formação científica, que visa proporcionar uma formação consistente no domínio do respetivo curso;

c) A componente técnica artística, que visa a aquisição e desenvolvimento de um conjunto de aprendizagens, conhecimentos, aptidões e competências técnicas e artísticas para o perfil profissional visado;

d) A formação em contexto de trabalho, quando exista, que visa a aquisição e o desenvolvimento de competências técnicas e artísticas, relacionais e organizacionais relevantes para a qualificação profissional a adquirir (Artigo $6^{\circ}, \mathrm{n}^{\circ} 2$, Portaria n ${ }^{\circ} 229-\mathrm{A} / 2018$, de 14 de agosto).

O curso secundário de música mantem as variantes de Instrumento, Formação Musical e Composição, assim como os tempos letivos, duração do curso e regimes de frequência.

\section{O Conservatório de Música de Braga Calouste Gulbenkian: um Novo Paradigma do Ensino da Composição}

O Conservatório de Música Calouste Gulbenkian de Braga é um caso único em Portugal no que diz respeito ao ensino da Composição, e do surgimento de novos compositores que concluíram o curso secundário de Composição. Segundo (Bastos, 2014, p. 226), estes, “[...] representam um novo paradigma da composição em Portugal”.

A inexistência de um curso de Composição levou a que o Conservatório Calouste Gulbenkian de Braga, gozando de um plano de estudos próprios, criasse, no ano letivo 2000/2001, o primeiro curso de Composição de nível secundário em Portugal. "Neste curso, constavam para além da disciplina tradicional de estudo geral na área da Composição, ATC, as novas disciplinas de Composição (disciplina nuclear do curso), Laboratório de Composição (LC) e Leitura de Partituras (LP)" (Bastos, 2014, p. 228). Uma outra dificuldade encontrada, centrou-se na inexistência de um programa de forma, que, houve necessidade de elaborar os programas de duas das três disciplinas do curso. Em seguida passo a mencionar os aspetos gerais do programa da disciplina de Composição:

[...] Esta disciplina abrange a compreensão da organização da matéria sonora ao longo dos tempos, que pode, no entanto, não exercer-se numa perspetiva histórica, para que haja um permanente enquadramento crítico articulado com as perspectivas do nosso tempo. $\mathrm{O}$ que se propõe não é uma viagem histórica até à atualidade, mas sim a concretização de técnicas de Composição empregues em todos os tempos e a sua articulação com problemas estilísticos atuais, e a partir dai tentar reconstruir o conceito de audição e escrita desde sempre. [...] a disciplina apela a que o aluno, mercê da prática de exercícios simples e outros trabalhos mais complexos, e sempre apelando à sua musicalidade/sensibilidade para a época e técnicas em causa, construa, participe, perceba e veja, de um modo mais personalizado, a problemática da tradição musical da qual ele é herdeiro (Bastos, 2014, p. 231).

O resultado deste processo conclui que o curso de Composição, no regime de ensino integrado no Conservatório de Música Calouste Gulbenkian de Braga, deu a oportunidade a vários jovens de desenvolverem a sua criatividade musical, orientados por professores especializados, de se formarem e prosseguirem estudos nos cursos superiores de música em Portugal e fora de Portugal, ou então seguirem a carreira de compositores.

\section{Considerações Finais}

Pelo exposto, verifica-se que o ensino da Composição, enquanto disciplina/curso das reformas aqui traduzidas, esteve sempre presente como aspeto central e nuclear do ensino da música em Portugal. Neste sentido, constata-se uma grande importância da Composição, e disciplinas análogas, nos planos de estudo das diferentes reformas que aconteceram ao longo dos tempos. No entanto, é de salientar que na reforma mais importante do sistema educativo (Decreto-Lei no $310 / 83$, de 1 de julho) - pelo menos a mais controversa -, o curso de Composição tenha desaparecido dos planos de estudo de nível geral e secundário, e apenas se tenha processado no âmbito do ensino superior. Tal situação foi revertida em 2012, através da Portaria no 243-B/2012, 
de 13 de agosto, no enanto, o ensino artístico especializado de música, no âmbito da Composição, ficou, assim, marcado por um vazio de vinte e nove anos, com consequências para a formação de jovens compositores.

A concretização deste artigo permitiu situar o Curso de Composição, no ensino artístico especializado da música de nível secundário, em Portugal ao longo dos tempos, e espera-se que seja útil para posteriores trabalhos de investigação. Concretamente, espera-se que este trabalho dê continuidade ao desenvolvimento da Tese de Doutoramento em Educação Artística (Educação Musical) do Instituto de Educação da Universidade do Minho, intitulada: O ensino da composição nas escolas públicas especializadas de música em Portugal no século XXI. Um estudo de caso múltiplo.

\section{Referências}

Amado, M. (1999). O prazer de ouvir música. Sugestões pedagógicas de audições para crianças. Editorial Caminho.

Bastos, P. (2014). Um novo paradigma da composição portuguesa. In: Vieira, Maria Helena \& Soutelo, Rudesindo (Orgs.). Percursos do Ensino da Música 2014. Arte Tripharia, p. 225-240.

Brito, M., \& Cymbron, L. (1992). História da Música Portuguesa.: Universidade Aberta.

Carneiro, H., \& Vieira, M. H. (2017). A disciplina de Formação Musical no ensino especializado da música em Portugal: contributos para a caraterização da sua identidade. Revista De Estudios E Investigación En Psicología Y Educación, (04), 145-150. https://doi.org/10.17979/reipe.2017.0.04.2769

Cruz, I. (1985). O que fiz e o que não fiz. Autor.

Freitas Branco, J. de (1995). História da Música Portuguesa. Europa-América.

Gomes, C. A. F. F. (2000). Contributos Para o Estudo do Ensino Especializado de Música em Portugal. 2000.147 f. Memória Final do CESE (Especialização em Direcção Pedagógica e Administração Escolar) - Escola Superior de Educação, Instituto Jean Piaget, Almada, Portugal.

Nogueira, M. J. P. G.(2016). O enquadramento da disciplina de Canto no Ensino Artístico Especializado em Portugal desde o século XVIII até à atualidade. Dissertação (Mestrado em Docência e Gestão da Educação) - Faculdade de Ciências Sociais e Humanas, Universidade Fernando Pessoa, Lisboa, Portugal.

Pacheco, A. (2013). O Ensino da Música em Regime Articulado. Projeto de Investigação-Ação no Conservatório do Vale do Sousa. Tese (Doutoramento em Estudos da Criança Especialidade Educação Musical) - Instituto de Educação, Universidade do Minho, Braga, Portugal.

Palheiros, G. B.(1993). Educação Musical no Ensino Preparatório - Uma Avaliação do Currículo. Edição APEM.

Portugal. Decreto nº 18 461, de 14 de junho de 1930 - Funde os Conservatórios de Música e de Teatro numa mesma instituição sob administração comum.

Portugal. Decreto n ${ }^{\circ} 18$ 881, de 25 de setembro de 1930 - Reestrutura o Conservatório Nacional e define os planos de estudos de ensino da música e do teatro.

Portugal. Decreto-Lei no 310/83, de 1 de julho - Insere o ensino artístico nos moldes gerais de ensino em vigor através da reconversão dos Conservatórios de Música em Escolas Básicas e Secundárias, criando as respetivas Escolas Superiores de Música inseridas na estrutura de Ensino Superior Politécnico.

Portugal. Portaria n 294/84, de 17 de maio - Aprova o plano de estudos dos Cursos Gerais de Música, a nível do ensino preparatório e ensino secundário unificado, assim como o plano de estudos do Curso Complementar de Música ao nível do ensino secundário.

Portugal. Portaria no 370/98, de 29 de junho - Faz a homologação dos cursos ministrados ao abrigo da Experiência Pedagógica de 71.

Portugal. Portaria n ${ }^{\circ}$ 243-B/2012, de 13 de agosto - Cria os cursos secundários artísticos especializados de Dança, de Música, de Canto e de Canto Gregoriano e aprova os respetivos planos de estudos ministrados em estabelecimentos de ensino público, particular e cooperativo.

Portugal. Decreto-Lei n ${ }^{\circ} 55 / 2018$, de 6 de julho - Estabelece o currículo dos ensinos básico e secundário, os princípios orientadores da sua conceção, operacionalização e avaliação das aprendizagens, de modo a garantir que todos os alunos adquiram os conhecimentos e desenvolvam as capacidades e atitudes que contribuem para alcançar as competências previstas no Perfil dos Alunos à Saída da Escolaridade Obrigatória.

Portugal. Portaria n ${ }^{\circ}$ 229-A/2018, de 14 de agosto - Procede à regulamentação dos cursos artísticos especializados de nível secundário, a que se refere a alínea c) do $\mathrm{n}^{\circ} 4$ do artigo $7^{\circ}$ do Decreto -Lei $\mathrm{n}^{\circ}$ 55/2018, de 6 de julho, designadamente dos cursos de Dança, de Música, de Canto e de Canto Gregoriano, tomando por referência a matriz curricular-base constante do anexo VII do mesmo decreto lei.

Ribeiro, A., \& Vieira, M. (2016). A articulação entre o ensino especializado da música e o sistema geral de ensino em Portugal: impacto actual da reestruturação de 2009. Opus, 22(1), 237-254. doi:http://dx.doi.org/10.20504/opus2016a2210

Severino, A. J. (2014). Metodologia do Trabalho Científico. Cortez Editora.

Vasconcelos, A. Â. (2002). O Conservatório de Música: Professores, organização e políticas. Instituto de Inovação Educacional.

Vosgerau, D., \& Romanowski, J. (2014). Estudos de revisão: implicações conceituais e metodológicas. Revista de Diálogo Educacional, (14)41, 165-189. 